\title{
SPERM MIGRATION AND CERVICAL MUCUS STUDIES IN INDIVIDUAL CYCLES
}

\author{
SABITA SUJAN,* JOHN DANEZIS $\uparrow$ AND AQUILES J. SOBRERO \\ Margaret Sanger Research Bureau, 17 West 16th Street, New York 11, U.S.A.
}

(Received 21st December 1962)

Summary. Sixty-five postcoital tests (PCT) were performed during twelve menstrual cycles, between 3 and $13 \mathrm{hr}$ after spontaneous sexual relations, on seven couples who consulted the Margaret Sanger Research Bureau complaining of infertility and who were selected for this study on the basis of repeated normal semen analyses, normal coital technique, and ovulatory cycles as determined by basic body temperature, vaginal smears, and endometrial biopsies; and the results were correlated with the quality of cervical mucus.

A rise was observed in both PCT results and quality of cervical mucus from a pre-ovulatory low to an ovulatory plateau, with a post-ovulatory deterioration of quality. The curves for cervical mucus and PCT paralleled each other, except that the PCT quality deteriorated more slowly than that of the cervical mucus.

The mucus from the cervical canal showed an increase in the proportion of normal (oval) spermatozoa of 5 to $15 \%$ over the figure reported for the corresponding masturbated semen specimens.

\section{INTRODUCTION}

In his paper on the postcoital test, Sims (1868) stated: "In the investigation of a case of sterility, we must determine whether the secretions of the cervical canal are favourable or not to the vitality of the spermatozoa." Sims pointed out that an important factor in evaluating the test is the day of the menstrual cycle when the contents of the cervix are examined.

These keen observations of a pioneer physician are the more noteworthy when one considers that no further observations in this field were published in the succeeding half-century, until Hühner (1913) published his book, Sterility in the Male and Female and its Treatment, in which he described the test which is now known as the Hühner Test or postcoital test.

Cyclic changes which occur in the mucus have been studied by several investigators (Williams, 1946; Stein \& Cohen, 1950; Bishop, 1953; Donald, 1953; Swyer, 1955; Danezis, Sujan \& Sobrero, 1962), and the results are usually given mainly in terms of composite averages in which the characteristics of individual behaviour become lost. Pommerenke \& Viergiver (1946) also stated that these cyclic changes are more clearly illustrated by individual curves than

\footnotetext{
* Present address: All India Institute of Medical Sciences, New Delhi 16, India.

† Present address: Alexandra State and University Hospital, Athens, Greece.
} 
by composite average curves, since the mid-period is shorter in duration for a given cycle.

The present study was undertaken to observe results of PCT in correlation with cyclic variations in quality and quantity of the cervical mucus as well as with the basal body temperature (BBT) records in individual cycles.

Reasons for unsatisfactory PCT, properly timed in the cycle, are: subnormal semen of poor motile quality, abnormal cervical mucus, inadequate coital technique, or any combination of these factors.

\section{MATERIALS AND METHODS}

Seven couples, who were being investigated at the Margaret Sanger Research Bureau for possible causes of their infertility, were selected for the present study. Selection was made on the basis of results of certain investigations which are routine at the Bureau: $\mathrm{BBr}$, vaginal smears, tubal insufflation and/or uterogram, and endometrial biopsies. Each husband was found on four different occasions to have a normal ejaculate (volume, concentration of spermatozoa, morphology and percentage of motile cells, and quality of motility). The standards at the Bureau for semen of good quality are: count over 60 million spermatozoa per millilitre; morphology $80 \%$ or more oval cells; over $60 \%$ motile cells with quality 3 or better, on a scale of 4 (MacLeod, 1953). By keeping these factors or variables within the accepted norm and thus eliminating them as a cause of infertility, it was thought that a better evaluation of our observations on cervical mucus and PCT was possible.

Six of the seven couples were cases of primary infertility, and all seven had been trying for 1 to 6 years to conceive. The age of the women ranged from 26 to 32 years and the men from 28 to 35 years.

A total of twelve complete menstrual cycles were observed. The couples had intercourse throughout the cycle, and PCT were performed after each coitus whenever possible, noting the quality of the cervical mucus. The women were instructed to keep records of their BBT and of any symptoms such as intermenstrual pain, bleeding or discharge. Data regarding days of abstinence, whether orgasm was achieved, and the time interval since coitus were recorded. Adequacy of the mechanical act of coitus was checked by a careful questioning of the wife at the time of each observation. The time interval between coitus and the PCT varied from 3 to $13 \mathrm{hr}$. One couple was observed for three cycles, three for two cycles, and three for one cycle. The number of PCT in each cycle varied from four to seven, and a total of sixty-five tests were studied. For the purpose of this study, the menstrual cycles were divided retrospectively, on the basis of BBT records, into three phases:

(1) Pre-ovulatory: From menses to the commencement of the ovulatory phase.

(2) Ovulatory: From $24 \mathrm{hr}$ prior to the thermal shift to $24 \mathrm{hr}$ thereafter.

(3) Post-ovulatory: The remaining part of the cycle.

In an attempt to evaluate the quality of cervical mucus, four factors were taken into account during each observation: amount, colour, Spinnbarkeit 
(SPK), and cellular content. Each of the four factors was assigned a numerical rating from 0 to 2. The highest obtainable rating was 8 (abundant, clear, SPK over $10 \mathrm{~cm}$, and no cells), the lowest 0 (scanty, opaque, sPK 0 to $1 \mathrm{~cm}$, with abundant cells), as shown in Table 1 .

The routine technique and classification of PCT, established by one of us (A.J.S.), as negative, poor, fair, good and excellent, are defined in Table 2.

TABLE 1

QUALITY OF GERVICAL MUCUS

\begin{tabular}{|c|c|c|c|c|}
\hline $\begin{array}{l}\text { Numerical } \\
\text { rating }\end{array}$ & Quantity & Colour & $\begin{array}{l}\text { SPK } \\
(\mathrm{cm})\end{array}$ & Cells \\
\hline 0 & Scanty & $\begin{array}{l}\text { Opaque, } \\
\text { yellowish }\end{array}$ & 0 to 1 & $\begin{array}{l}\text { More than } 5 \text { per } \\
\text { low power field } \\
\text { (LPF }=\times 120)\end{array}$ \\
\hline 1 & Moderate & $\begin{array}{l}\text { Opalescent, } \\
\text { whitish }\end{array}$ & 1 to 10 & 1 to 5 per LPF \\
\hline 2 & Abundant & $\begin{array}{l}\text { Clear, } \\
\text { watery }\end{array}$ & Over 10 & $\begin{array}{l}\text { Less than } 1 \text { per } \\
\text { LPF }\end{array}$ \\
\hline
\end{tabular}

TABLE 2

PCT GLASSIFICATION USED AT THE MARGARET SANGER RESEARGH BUREAU

\begin{tabular}{|c|c|}
\hline Negative & $\begin{array}{l}\text { No spermatozoa found in any specimen of endocervical mucus or of vaginal } \\
\text { fluid. }\end{array}$ \\
\hline Poor & Spermatozoa present, but none motile in the endocervical mucus specimen. \\
\hline Fair & $\begin{array}{l}\text { Up to five spermatozoa with motility of Grade } 3 \text { or better per high power } \\
\text { field (HPF }=\times 400 \text { ) or any number of spermatozoa with motility less than } \\
\text { Grade 3-in the endocervical mucus specimen. }\end{array}$ \\
\hline Good & $\begin{array}{l}\text { Six or more spermatozoa per HPF with motility of Grade } 3 \text { or better in } \\
\text { endocervical mucus specimen. }\end{array}$ \\
\hline Excellent & $\begin{array}{l}\text { Over fifteen spermatozoa per HPF with motility of Grade } 3 \text { or better in } \\
\text { endocervical mucus specimen. }\end{array}$ \\
\hline $\begin{array}{l}\text { Grades of } \\
\text { The at } \\
\text { would in }\end{array}$ & $\begin{array}{ll}\text { Serm motility } \\
0 & \text { No motion. } \\
0 & \text { Slow waving of tail, without forward motion. } \\
1 & \text { Slow progressive movements-not necessarily forward motion. } \\
2 & \text { More active, with forward motion. } \\
3 & \text { Good forward motion. } \\
4 & \text { Very active - fastest speed observed in vitro. } \\
\text { ve grades can be subdivided by the addition of }+ \text { or }- \text {; for instance, Grade } 3- \\
\text { cate a motility better than Grade } 2+\text { but not quite Grade } 3 \text {. }\end{array}$ \\
\hline
\end{tabular}

At the time of each PGT, a sample of the endocervical mucus was taken after carefully wiping from the portio and external cervical os any mucus protruding from it. The sample of mucus was taken by suction with a tuberculin syringe (without cannula or needle), placed on a clean glass slide, and spread with a coverslip. After qualities of mucus and of PCT had been noted, the slide was fixed in ether-alcohol, stained by the Papanicolaou technique, and examined under oil immersion for morphological evaluation of spermatozoa which had penetrated the cervical mucus. 


\section{OBSERVATIONS}

Of the twelve cycles studied, nine graphic records have been selected which are representative (Text-figs. 1 to 9). Each graph shows the relation between BBT, cervical mucus, and PCT. The abscissa represents the day of the menstrual cycle, and on the ordinate the BBT is represented by a solid line, the quality of cervical mucus by a dotted line, and the PCT quality by a broken line. Circles

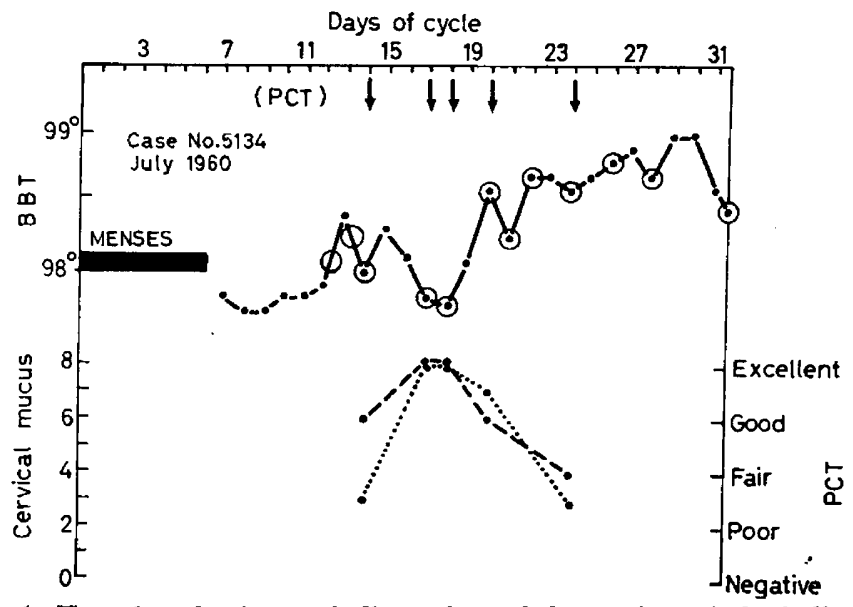

Text-Fig. 1. Type 1 cycle. Arrows indicate days of observation; circles indicate occurrence of coitus; asterisk indicates pregnancy. Solid line represents BBT; broken line the PCT quality; dotted line the quality of cervical mucus.

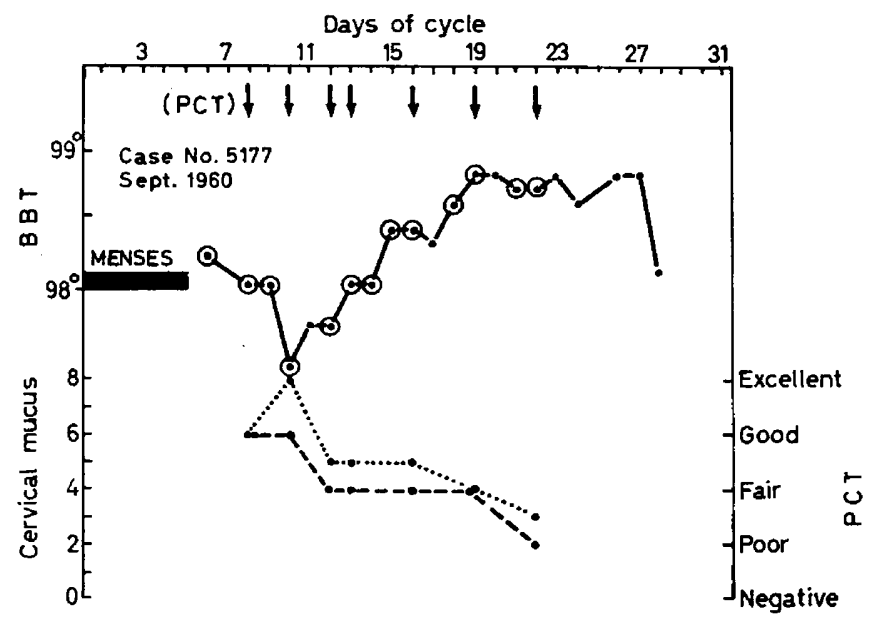

Text-Fig. 2. Type 1 cycle. Symbols as in Text-fig. 1.

on the BBT line indicate coitus, and arrows the days when the observations were made.

\section{GHANGES IN THE CERVICAL MUCUS}

The sixty-five PCT and cervical mucus observations, scattered through twelve ovulatory cycles, were evaluated according to the scales used routinely in our clinic (Tables I and 2). When the results so obtained for each cycle were plotted, 
it was found that the resulting curves could be roughly grouped as of four types. This grouping was made solely for convenience in analysing and presenting the results here reported, and should by no means be construed as an attempt to establish classifications for the cyclic changes of cervical mucus in ovulatory cycles. Such a classification could be made - if at all-only on the basis of a more extensive number of cases similarly studied.

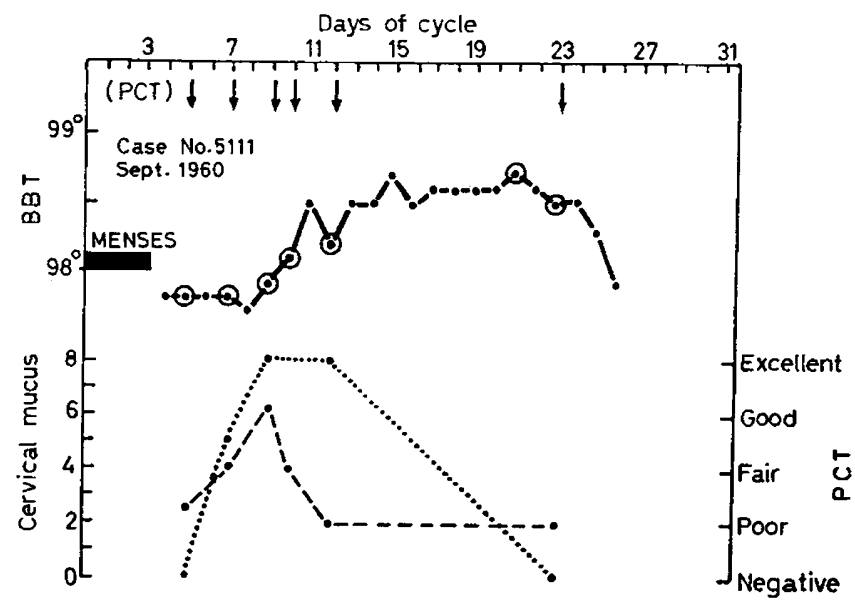

Text-rig. 3. Type 1 cycle. Symbols as in Text-fig. 1 .

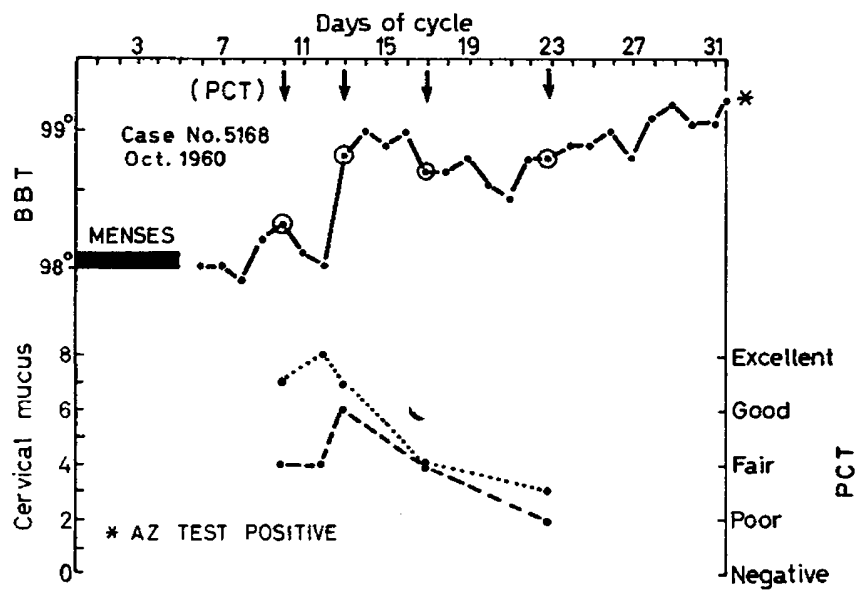

Text-Fig. 4. Type 1 cycle. Symbols as in Text-fig. 1.

Type 1 (Text-figs. I to 4). In a group of seven menstrual cycles observed in four different women, definite changes were noted in the cervical mucus. This variation, measured in the way previously stated, ranged from 0 to 8 . From scanty-opaque-viscid-cellular, the mucus changed to abundant-clear-wateryacellular as the days of observation approached the time of ovulation, after which the mucus reverted to the former type with poor physical characteristics. In this most typical group, the peak of good mucus quality coincided well with 
the ovulatory phase. Four of these seven typical cycles are represented in Text-figs. 1 to 4 , one of them (Text-fig. 4) being a conception cycle, as shown by the sustained elevation of post-ovulatory temperature.

Type 2 (Text-figs. 5 and 6). In two cycles, observed in two patients, the quality of the cervical mucus never exceeded a rating of 5 at its best during the ovulatory phase, while variations below 5 were noted in the pre- and post-

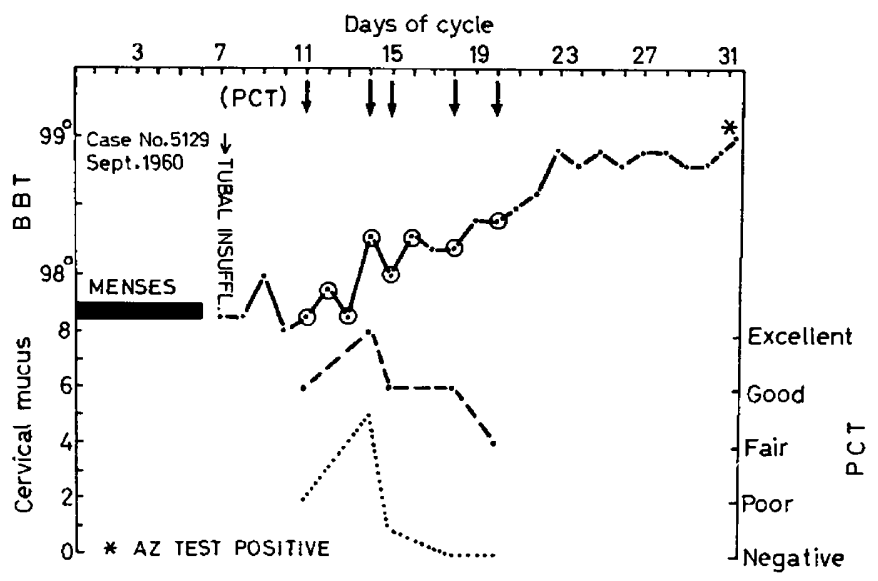

Text-Fig. 5. Type 2 cycle. Symbols as in Text-fig. 1 .

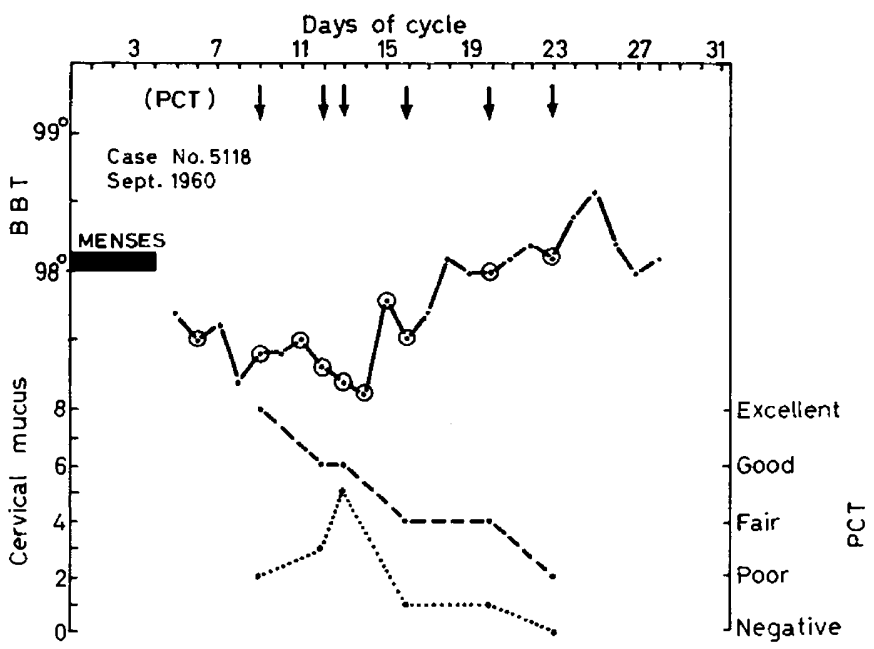

TeXt-Fig. 6. Type 2 cycle. Symbols as in Text-fig. 1.

ovulatory phases. In Text-fig. 5 (a conception cycle), the rise in quality of cervical mucus and of $\mathrm{PGT}$, synchronous with changes in $\mathrm{BBT}$, is particularly well shown. During this short period of time, a comparative increase in the amount of cervical mucus and a reduction in the number of cellular elements were noted in the fresh mucus sample examined at the time of the PCT, which were confirmed by examination of fixed and stained preparations. 
Type 3 (Text-figs. 7 and 8). Two cycles, in two different patients, showed the variations in cervical mucus described as Type 1, with the exception that towards the end of the cycle an improvement in the quality of cervical mucus was noted (on Day 21 in Text-fig. 7, on Day 27 in Text-fig. 8). These changes in the mucus were not preceded by changes in the BBT. The second improvement in mucus quality in the same cycle very probably reflects the pre-men-

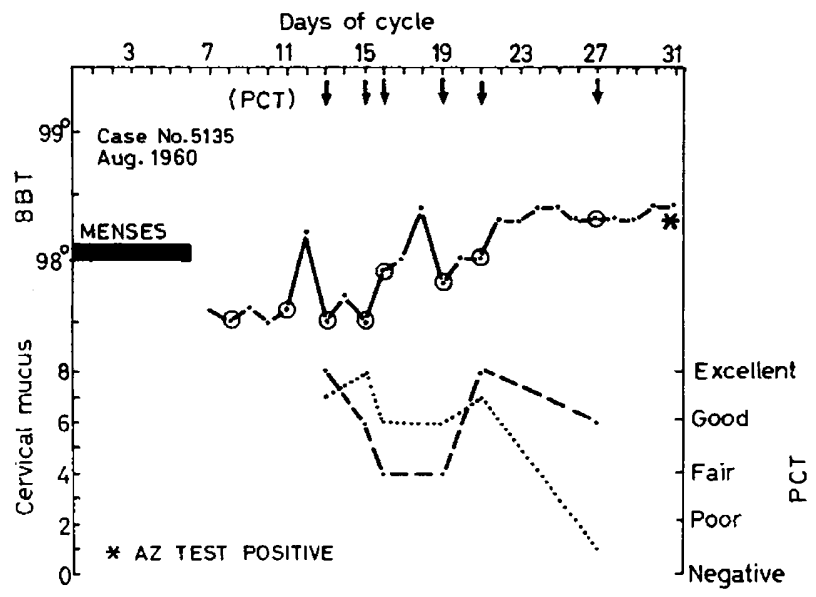

Text-FIG. 7. Type 3 cycle. Symbols as in Text-fig. 1.

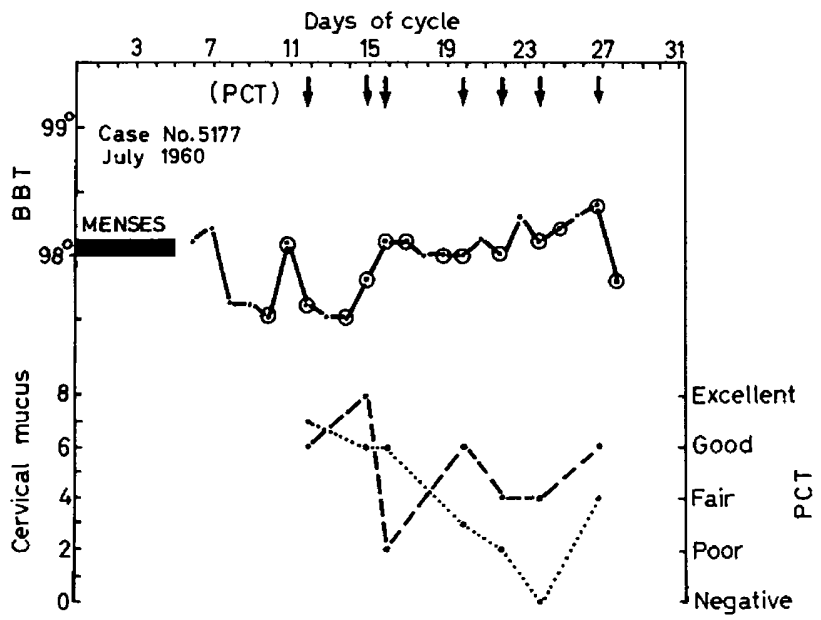

TexT-FIG. 8. Type 3 cycle. Symbols as in Text-fig. 1.

strual increase in the titre of blood oestrogen described by Markee \& Berg (1944) and Littrell \& Tom (1947). Text-fig. 7, it is to be noted, was a conception cycle.

Type 4 (Text-fig. 9). In one cycle, the cervical mucus of ovulatory type (rated 8) was seen to persist from Day 12 to Day 21 of a 29-day cycle, although BBT fell on Days 15 and 17. 
In the twelve cycles studied, a total of sixty-five observations were made of cervical mucus after coitus. As shown in Text-fig. 10, each observation, classified according to the numerical ratings mentioned above, was plotted against the day of the observation. The average value of the observations was

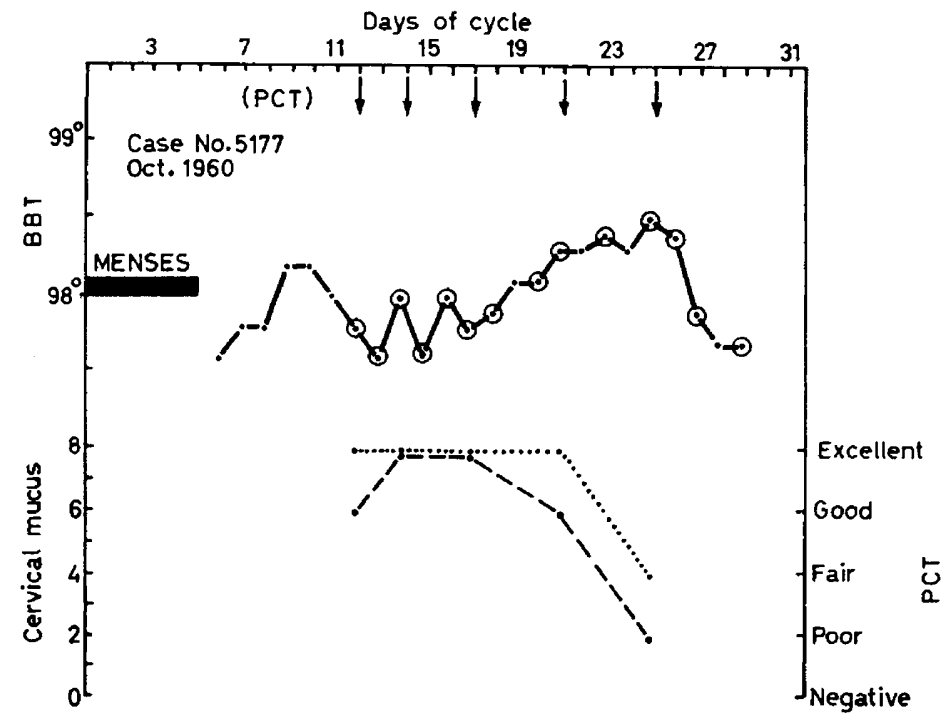

Text-FrG. 9. Type 4 cycle. Symbols as in Text-fig. 1.

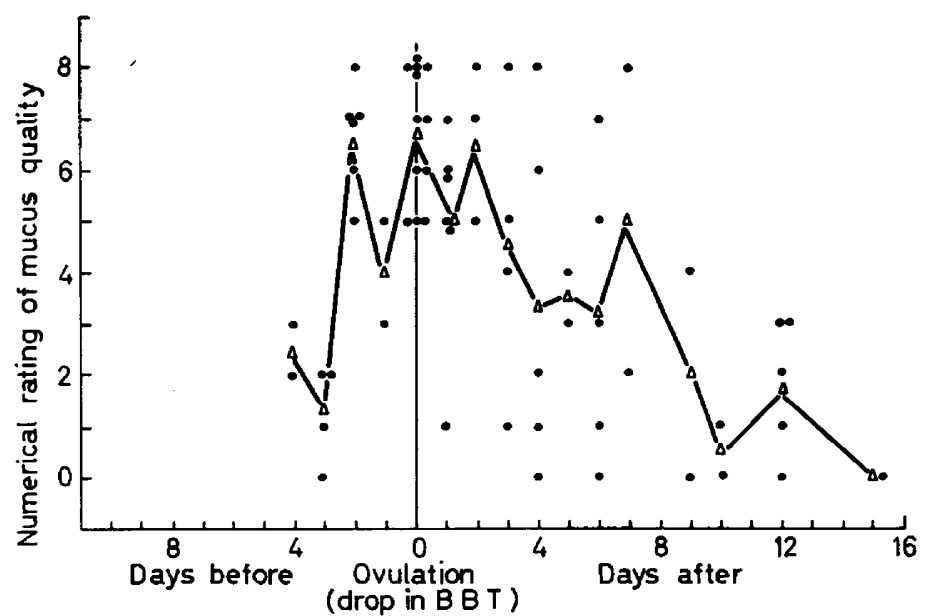

TEXT-FIG. 10. Variations in average quality of cervical mucus in sixty-five PCT and their relation to phase of cycle. Dots indicate individual observations; triangles indicate composites.

taken as representative of each day of the cycle, and a curve was traced showing the variations observed in the quality of cervical mucus. The curve showed the highest values towards the time of ovulation, while lower values were seen at the other two phases of the menstrual cycle. 
In nine cycles, an improvement in the quality of the PCT occurred around the ovulatory phase of the cycle as determined by the BBT, while the PCT of poorer quality were observed at other times of the cycle.

The four cases represented by the curves of Text-figs. 1 to 4 may be considered typical. Some deviation may be seen in cases whose curves are shown in Text-figs. 5 to 9 . In the cycle shown in Text-fig. 6 , for example, the PCT of excellent quality was seen only during the pre-ovulatory phase, with deterioration thereafter.

In spite of these deviations, when the daily average PCT ratings are plotted, one gets the picture presented by Text-fig. 11 . It is evident that, on the average,

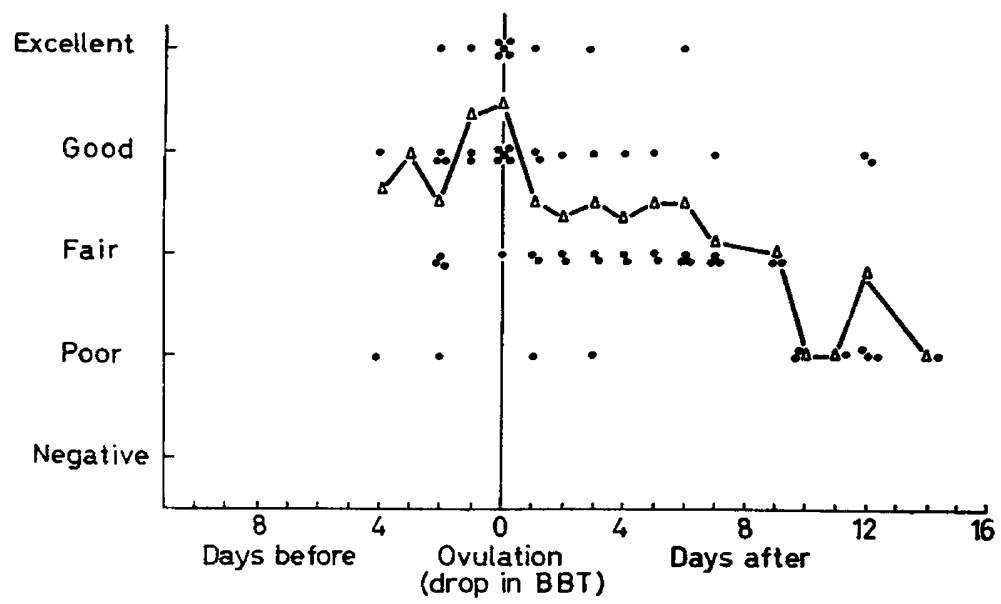

Text-Fig. 11. Variations in average quality of sixty-five PCT and their relation to cycle phase in seven infertile couples. Symbols as in Text-fig. 10.

the quality of the PCT rises from a pre-ovulatory low to an ovulatory plateau, followed by a marked post-ovulatory drop. Only two 'poor' PCT cases were reported in the ovulatory phase and no negative PCT was ever encountered in any phase; i.e. the sixty-five entries in Text-fig. 11 were all positive.

Of special interest is the correspondence between the curve for mucus quality, shown in Text-fig. 10, and that of PCT quality shown in Text-fig. 11.

As previously stated, the masturbated semen specimens of the husbands showed $80 \%$ or more oval spermatozoa. The cervical mucus samples were examined for morphology of the migrated spermatozoa, 100 of which were studied in each PGT. Normal (oval) as well as abnormal sperm cells found in the masturbated specimens of semen were also seen in the stained slides of postcoital cervical mucus. However, it was consistently noted that in the stained slides, the percentage of oval sperm cells was always higher than that reported for the masturbated semen specimens. The improvement in percentage of oval spermatozoa over the percentage in the masturbated specimen ranged from 5 to $15 \%$ in all the observations. This percentage of improvement did not vary with the different phases of the menstrual cycle. 


\section{DISCUSSION}

Among the many studies of sperm migration and changes in cervical mucus, only a few have reported on individual cycles. Romberg (1957) in his observations found "clear, watery, cervical fluid" in $75 \%$ in the ovulatory phase, and $25 \%$ in the other two phases. Our study shows similar results. In eight cycles $(67 \%)$, appearance of the ovulatory type of mucus corresponded with the thermal shift of the BBT. In the remaining four cycles (33\%), the best quality of cervical mucus was noted in the pre-ovulatory phase, 1 to 3 days prior to the drop in the BBT, and never in the post-ovulatory phase.

Stein \& Cohen (1950), in their study on twenty-five women, found "pre- and post-menstrual thickening of cervical mucus inimical to sperm", and they "would prefer to add the quality of penetrability and longevity of spermatozoa as a more definite sign of ovulation". Observations of Berman (1953) on thirty-one women suggest that spermatozoal penetration can only occur during the "watery phase of the cervical mucus", a phase which, according to him, "immediately precedes and coincides with the thermal shift, as determined by the BBT recording".

In seven out of the twelve cycles in this series (Text-figs. 1 to 4 ), ovulatory type of mucus and excellent or good PCT corresponded with the ovulatory phase. In two cycles (Text-figs. 5 and 6), cervical mucus failed to reach the quality considered most favourable-abundant, watery, acellular-during the cycle studied, and yet PCT quality was either good or excellent during the ovulatory phase. In two other cycles (Text-figs. 7 and 8 ), variations observed in the cervical mucus quality were not correlated with the changes seen in the PCT quality; irrespective of the phase of the menstrual cycle in which the PCr was done, PCT of good or excellent quality were seen even when the mucus was of a poor quality. In the remaining cycle (Text-fig. 9) the mucus was ovulatory in character from Day 12 to Day 21, yet the quality of PCT was excellent only during the ovulatory phase and was comparatively poor in the pre- and post-ovulatory phases.

Comparing the average curves of sixty-five observations of cervical mucus and PCT results (see Text-figs. 10 and 11), we found that they followed similar patterns which corresponded more closely during the ovulatory and postovulatory phases, the curve representing the PCT quality being more gradual than the one representing the quality of the cervical mucus.

In general, 'ovulatory phase', as indicated by abrupt temperature change, corresponded in these figures to cervical mucus of higher ratings and PGT of good or excellent quality. This, when compared with studies based on larger samples by several investigators (Williams, 1946; Stein \& Cohen, 1950; Bishop, 1953; Danezis et al., 1962), shows that the direct relationship apparent between the PCT results and the cervical mucus when studied in individual cycles is hidden in the composite analysis of large series. Our results tend to emphasize the importance of repeated PCT observations to study the changes in cervical mucus and spermatozoal penetration during individual menstrual cycles. In the three conception cycles studied, all PGT were of either good or excellent quality during the ovulatory phase, although the mucus was of poor quality in one of the three. 
Although Abarbanel (1946) observed that "grossly abnormal sperm not only penetrated but lived almost as long in the cervical mucus as they did in the semen", Cohen \& Stein (1951), Romberg (1957) and MacLeod, Martens, Silberman \& Sobrero (1959) reported that the stained smears of mucus showed a remarkable reduction in the percentage of abnormal spermatozoa in comparison to the husband's prior semen analyses. Our results, similar to those of Romberg (1957), showed a superiority of 5 to $15 \%$ in the morphology of the spermatozoa which were able to penetrate the cervical mucus, as compared to the masturbated semen specimens in all three phases of the menstrual cycle.

\section{ACKNOWLEDGMENTS}

One of us (S. S.) is indebted to the Abraham Stone Fellowship Fund for financial support; another of us (J. D.) wishes to acknowledge a grant from the International Co-operation Administration under the Visiting Research Scientists Program administered by the National Academy of Sciences of the U.S.A.

\section{REFERENCES}

Abarbanel, A. R. (1946) Spermatozoa and cervical mucus. The Problem of Fertility, p. 121. Ed. E. T. Engle. Princeton University Press, Princeton, New Jersey.

Bergman, P. (1953) Spermigration and cyclic changes in cervical mucus. Fertil. Steril. 4, 183.

Btshop, P. M. F. (1953) Post-coital tests. Mammalian Germ Gells, p. 275. Ed. G. E. W. Wolstenholme. Little, Brown, Boston.

Conen, M. R. \& Stein, I. F. (1951) Sperm survival at estimated ovulation time. Comparative morphology: relative male infertility. Fertil. Steril. 2, 20.

Danezis, J., Sujan, S. \& Sobrero, A. J. (1962) Evaluation of the postcoital test. Fertil. Steril. 13, 559.

Donald, I. (1953) Results of post-coital tesis where pregnancy ensued. Mammalian Germ Cells, p. 287. Ed. G. E. W. Wolstenholme. Little-Brown, Boston.

HüHNER, M. (1913) Sterility in the male and female. Rebman, New York.

Litrrell, L. \& Tом, J. Y. S. (1947) Fluctuations in the estrogen level throughout the menstrual cycle of one woman. Endocrinology, 40, 292.

MacLeod, J. (1953) The male contribution to human infertility. Ann. Obstet. Ginec. 6, 120.

Macleod, J., Martens, F., Silberman, C. \& Sobrero, A. J. (1959) The post-coital and post-insemination cervical mucus and seminal quality. Stud. Fertil. 10, 41.

MarkeE, J. E. \& Berg, B. (1944) Cyclic fluctuations in blood estrogen as a possible cause of menstruation. Stanford Med. Bull. 2, 55.

Pommerenke, W. T. \& Viergiver, E. (1946) Cervical mucus and the menstrual cycle. The Problem of Fertility. Ed. E. T. Engle. Princeton University Press, Princeton, New Jersey.

Romberg, G. H. (1957) Postcoital cytologic studies of endocervical and endometrial fluids. Fertil. Steril. 8, 164.

Sims, J. M. (1868) Illustrations of the value of the microscope in the treatment of the sterile condition. Brit. med. F. ii, 465, 492.

Stein, I. F. \& COHEN, M. R. (1950) Sperm survival at estimated ovulation time: prognostic significance. Fertil. Steril. 1, 169.

SwYer, G. I. M. (1955) Observations on the post-coital test. Stud. Fertil. 7, 79.

Williams, W. W. (1946) Interpretation of post-coital examinations of cervical mucus. Proceedings of the Conference on Diagnosis in Sterility, p. 154. Ed. E. T. Engle. Thomas, Springfield, Illinois. 